\title{
CARACTERIZAÇÃO MORFOLÓGICA DE FRUTOS, SEMENTES E GERMINAÇÃO DE Allophylus edulis (ST.-HIL.) RADLK. (SAPINDACEAE) ${ }^{1}$.
}

\author{
DANIELACLEIDEAZEVEDO DEABREU ${ }^{2}$, YOSHIKO SAITO KUNIYOSHI ${ }^{3}$, ANTONIO CARLOS NOGUEIRA4 $^{4}$, \\ ANTONIOCARLOSDESOUZAMEDEIROS 5
}

\begin{abstract}
RESUMO - Os objetivos deste trabalho foram caracterizar morfologicamente as estruturas externa e interna dos frutos e das sementes, além de descrever e ilustrar a morfologia externa da plântula de Allophylus edulis (St.-Hil.) Radlk.. Para a descrição dos frutos foram observados detalhes externos e internos do pericarpo, referentes à textura, consistência, cor, pilosidade, brilho, forma, número de sementes por fruto e deiscência. Para as sementes foram analisadas as seguintes variáveis externas: dimensões, cor, textura, consistência, forma e posição do hilo e da micrópila. Para as características internas, verificou-se presença ou ausência de endosperma, o tipo, a forma, a cor, a posição dos cotilédones, o eixo-hipocótilo-radícula e plúmula. A germinação foi considerada desde a emissão da radícula até a emissão dos protófilos e a plântula foi considerada estabelecida quando os protófilos já estavam totalmente expandidos. Os frutos de Allophylus edulis são do tipo coca, globosa, indeiscentes e monospérmicos. As sementes são ovóides, sem endosperma e o embrião ocupa toda a semente, mais ou menos encurvado e levemente comprimido. A germinação das sementes tem início ao oitavo dia e pode ser encerrada no décimo quinto dia, após a semeadura.
\end{abstract}

Termos para indexação: espécie florestal, morfologia interna e externa, plântula.

\section{MORPHOLOGICAL CHARACTERIZATION OF FRUITS, SEEDS AND GERMINATION OF Allophylus edulis (St.- Hil.) Radlk. (SAPINDACEAEA) ${ }^{1}$}

\begin{abstract}
The aim of this research was to characterize morphologically internal and external structures of fruits and seeds and to describe and illustrate the external seedling morphology of Allophylus edulis (St.-Hil.) Radk. from seed germination. In order to describe fruits, internal and external details related to texture, consistency, color, pilosity, brightness, shape, number of seeds per fruit and shedding were observed. Some external aspects of seeds were analyzed, including size, color, texture, consistency, shape, hilum and micropyle position. Regarding the internal characteristics the endosperm presence or absence and cotyledon, embryo axes and plumule type, shape and color. Germination was considered from radicle protrusion to the protophilus emission and seedlings were considered stable when all the protophilus were expanded. The fruits of Allophylus edulis are of the type coca, globose, indehiscent and monospermic. The seeds are ovoid, without endosperm and the embryo occupies the whole seed, more or less bent and slightly tablet. The germination of the seeds has beginning to the eighth day and it can be contained in the fifteenth day, after to planting.
\end{abstract}

Index terms: forest specie, internal and external structure, seedling.

\footnotetext{
${ }^{1}$ Submetido em 09/03/2004. Aceito em 04/05/2005. Parte da Dissertação de Mestrado do primeiro autor.

${ }^{2}$ Bióloga, MSc. em Ciências Florestais da UFPR, Bolsista CAPES, CuritibaPR.daniela@cnpf.embrapa.br

${ }^{3}$ Naturalista, Dr ${ }^{\text {a }}$, Depto. de Ciências Florestais da UFPR, Curitiba-PR.
}

yoshiko@floresta.ufpr.br

${ }^{4}$ Eng. Florestal, Dr., Depto. de Ciências Florestais da UFPR, Curitiba-PR. nogueira@floresta.ufpr.br

${ }^{5}$ Eng. Agrônomo, PhD, Pesquisador da Embrapa-Florestas, Colombo- PR. medeiros@cnpf.embrapa.br 


\section{INTRODUÇÃO}

Allophylus edulis (St.-Hil.) Radlk. também conhecido por vacum, chal-chal, fruta-de-pombo, baga-de-morcego e pau-de-pedreira tem distribuição geográfica compreendendo a Guiana, Bolívia, Paraguai, Uruguai e Argentina. Em território brasileiro é característica da Floresta Ombrófila Mista, Floresta Estacional Decidual e Floresta Estacional Semidecidual. Distribui-se na região do Amazonas e nos Estados do Ceará, Bahia, Mato Grosso, Minas Gerais, Rio de Janeiro, São Paulo, Paraná, Santa Catarina e Rio Grande do Sul, onde ocorre nos estratos médios das Florestas da Bacia do Alto Uruguai no extremo noroeste do Estado, na Floresta do Planalto (floresta dos pinhais) abrangendo a área nordeste do Estado com a presença de Araucaria angustifolia Kuntze. Ocorre na Floresta da Bacia do Rio Jacuí (Depressão Central), abrangendo a metade do centro-oeste do Estado e a Área do sudeste Riograndense (Escudo Riograndense), sendo menos freqüente na Floresta Atlântica (Reitz et al., 1988; Sanchotene, 1989; Backes e Nardino, 1999).

Allophylus edulis tem importância econômica por possuir madeira de boa qualidade, com aplicação na marcenaria, cabo de ferramentas, esteios, moirões, uso interno, lenha e carvão. É indicada para arborização urbana, tem boa capacidade de regeneração natural, crescimento rápido, sem exigências quanto às características do solo. Seu uso tem sido sugerido na recuperação de ecossistemas degradados (Lorenzi, 1992; Longhi, 1995). Associadas a essas características, a espécie desempenha papel fundamental na manutenção da fauna, ao produzir grande quantidade de frutos apreciados por animais, que se encarregam da dispersão das sementes (Sanchotene, 1989). Os frutos de $A$. edulis quando maduros são adocicados, comestíveis e quando fermentados produzem uma bebida conhecida como "chicha" (Reitz et al., 1988). Tanto os frutos como as folhas têm propriedades medicinais. O chá das folhas é usado em inflamações da garganta, problemas intestinais, diarréias e problemas digestivo. As folhas em cozimento são utilizadas para lavar feridas e contra a pressão alta (Körbes, 1995; Franco e Fontana, 2001).

As sementes, algumas vezes, têm características básicas para a identificação de famílias ou até mesmo do gênero, espécie ou variedade à qual a planta se subordina; mas freqüentemente, elas são apenas um elemento a mais na cadeia de caracteres que servem para identificar uma planta (Barroso, 1978). Entretanto, na Botânica Sistemática, somente os caracteres de planta adulta são freqüentemente utilizados, enquanto as características das plântulas são pouco utilizadas, talvez pela limitação de dados e falta de tradição (Donadio e Demattê, 2000).

O conhecimento das estruturas morfológicas do fruto, da semente e das plântulas florestais é importante para diversos fins como: nos laboratórios de análise de sementes, na identificação e na diferenciação de espécies, no reconhecimento da planta no campo, na taxonomia e na silvicultura, havendo necessidade de estímulos a esses estudos básicos (Amorim, 1996). O fruto e a semente podem fornecer indicações sobre o tipo de armazenamento, viabilidade e métodos de semeadura (Kuniyoshi, 1983). Da mesma forma, contribuem para uma correta interpretação dos testes de germinação e à realização de trabalhos científicos (Araújo e Matos, 1991). Auxiliando ainda na compreensão da dinâmica de populações vegetais, bem como, o reconhecimento do estágio sucessional em que a floresta se encontra (Oliveira, 1993; Donadio e Demattê, 2000).

Vários estudos sobre a morfologia de frutos e sementes têm sido desenvolvidos, muitos deles de forma parcial e essencialmente limitada à descrição de suas formas mais gerais (Amorim, 1996). Contudo, alguns autores desenvolveram estudos com grande diversidade de espécies florestais que permitem informações amplas e complexas dessas espécies. Como exemplo, Kuniyoshi (1983) que descreveu 25 espécies arbóreas da Floresta Ombrófila Mista, fornecendo as características dos frutos, das sementes e do desenvolvimento das plântulas. Barroso et al. (1999) analisou e descreveu a morfologia externa e interna de frutos e sementes de várias famílias de dicotiledôneas.

Amorim (1996) caracterizou e descreveu a morfologia de frutos, sementes, germinação, plântulas e mudas de espécies florestais da região de Lavras, no Estado de Minas Gerais. Beltrati (1973) ilustrou e descreveu a morfologia das sementes e a germinação de 18 espécies de Eucalyptus e Feliciano (1989) estudou a germinação de sementes e o desenvolvimento da muda, acompanhado de descrições morfológicas de 10 espécies arbóreas do semi-árido nordestino.

Silva et al. (1995) estudaram a morfologia do fruto, da semente e o desenvolvimento de plântulas, descrevendo plântulas normais e anormais de Luetzelburgia auriculata Duck. e Pterogyne nitens Tul.. Amorim et al. (1997) estudaram as características internas e externas dos frutos e sementes de Trema micrantha (L.) Blum., concluindo que estas características contribuem para o seu reconhecimento no campo. Estudos de frutos e sementes de Cryptocaria moschata Nees \& Martius., Endlicheria paniculata (Sprengel) MacBride 
e Ocotea catharinensis Mez., foram realizados por Moraes e Paoli (1996). Ferreira et al. (1998) caracterizaram os aspectos morfológicos externos e internos do fruto, e morfologia externa da plântula e da muda de Dipteryx alata Vogel.

Vários autores classificam os frutos de Allophylus edulis de forma diferenciada, como por exemplo, drupas obovadas ou obovada-orbiculares de base aguda e ápice arredondado (Sanchotene, 1989). Outras classificações como coco, obovóide (Reitz, 1980) ou cocas globosas, indeiscentes, com pericarpo carnoso, geralmente vermelho e de pouca espessura (Barroso et al., 1999) ou bagas ovóides (Longhi, 1995). De acordo com esse autor as sementes são ovaladas e de coloração branca. Os frutos são de coloração verde, quando imaturos, passando para amarela e finalmente vermelha quando maduros (Reitz et al., 1988; Lorenzi, 1992; Longhi, 1995).

Barroso et al. (1999) citam que na família Sapindaceae, o embrião de Allophylus sp. é semelhante ao do gênero Serjania sp. e a caracterizam como mais ou menos encurvado, com cotilédones crassos, incumbentes e um deles plicado transversalmente; o eixo-hipocótilo-radícula é sempre curto. Sanchotene (1989) afirma que o embrião tem coloração branca e os cotilédones são esverdeados.

Este trabalho teve por objetivos caracterizar morfologicamente as estruturas externa e interna dos frutos e das sementes, além de descrever e ilustrar a morfologia externa da plântula de Allophylus edulis.

\section{MATERIAL E MÉTODOS}

Os frutos de Allophylus edulis (St.-Hil.) Radlk. foram coletados em dezembro de 2000, de doze matrizes no município de Colombo - PR. A região é caracterizada por clima tipo Cfb (Köepen), altitude de $920 \mathrm{~m}$, a 2520'S e $49^{\circ} 14^{\prime} \mathrm{W}$, com precipitação média anual de $1500 \mathrm{~mm}$.

Amostras de galhos com frutos de $A$. edulis foram herborizadas e secadas em estufa elétrica. As exsicatas se encontram no Herbário de Dendrologia do curso de Engenharia Florestal da Universidade Federal do Paraná e estão acondicionadas em latas de zinco e registradas sob o n. ${ }^{\circ} \mathrm{EFC}$ 4644 .

A caracterização morfológica dos frutos e das sementes de A. edulis foi realizada no Laboratório de Sementes Florestais do Departamento de Ciências Florestais da Universidade Federal do Paraná. Para descrever e ilustrar, morfologicamente frutos e sementes, foram utilizados 100 unidades aleatoriamente. As observações foram realizadas com lupa de mesa estereoscópica e a olho nu. Anotando-se as medidas de comprimento, largura e espessura, com auxílio de um paquímetro digital, expressas em milímetro. Considerou-se o comprimento, tanto dos frutos como das sementes, a distância entre a base e o ápice; para a largura o lado mais largo e a espessura o lado mais estreito. Para a descrição dos frutos foram observados detalhes externos e internos do pericarpo, referentes à textura, consistência, cor, pilosidade, brilho, forma, número de sementes por fruto e deiscência. Para as sementes foram feitos cortes transversais e longitudinais com lâminas de bisturi. Foram analisadas as seguintes variáveis das sementes: externas - dimensões, cor, textura, consistência, forma e posição do hilo e da micrópila; internas - presença ou ausência de endosperma, o tipo, a forma, a cor, a posição dos cotilédones, o eixo-hipocótiloradícula e a plúmula em relação à semente.

Para o acompanhamento das fases de germinação foram semeadas seis repetições de 12 sementes, em rolo de papel na temperatura constante de $25^{\circ} \mathrm{C}$, na presença de luz contínua e em germinador do tipo Mangelsdorf. A germinação foi considerada desde a emissão da radícula até a emissão dos protófilos e a plântula foi considerada estabelecida quando os protófilos já estavam totalmente expandidos.

O procedimento metodológico para a morfologia de $A$. edulis foi baseado nos trabalhos de Barroso (1978), Kuniyoshi (1983), Feliciano (1989), Beltrati (1992), Chaves (1994), Amorim (1996), Barroso et al. (1999) e Vidal e Vidal (2000).

O material utilizado nos estudos morfológicos foi conservado em álcool etílico a $70 \%$ e as ilustrações foram feitas manualmente de material bem desenvolvido e representativo de cada fase.

\section{RESULTADOS E DISCUSSÃO}

a) Morfologia do fruto: coca, globosa, indeiscente, de consistência carnácea e monosperma. De acordo com a classificação de Barroso et al. (1999), a coca ou mericarpo é derivado do fruto esquizocarpáceo. Este é formado de dois ou mais carpelos concrescentes, originados de um ovário súpero ou ínfero, com placentação axial, que se decompõe longitudinalmente na maturação, em unidades de dispersão, tantas quantas são os carpelos componentes. Cada carpelo separa-se dos demais, formando um fruto parcial denominado coca ou mericarpo. Epicarpo glabro, com superfície lisa e brilhante, quando maduro. A coloração do fruto varia de acordo com o grau de maturação, modificando de verdeescuro e amarelo-laranja ao vermelho vivo, quando maduro (Figura 1A e 1D). Epicarpo e mesocarpo constituem a parte 


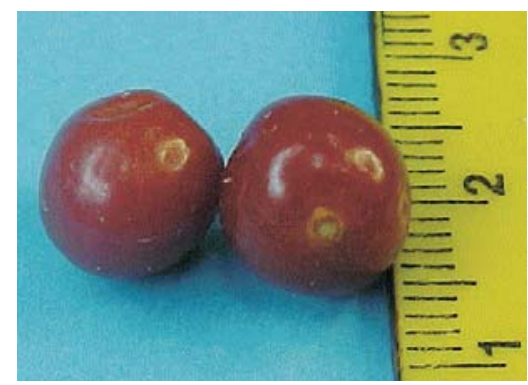

A

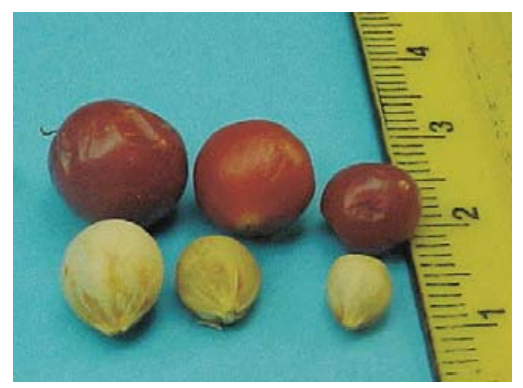

C

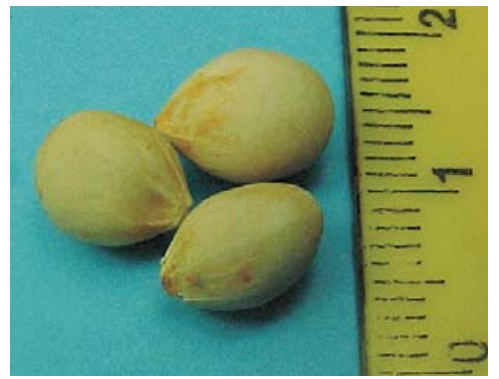

B

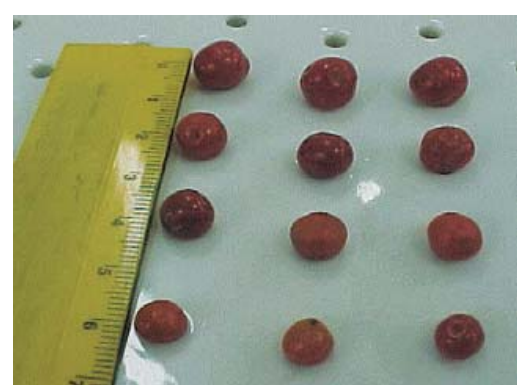

$\mathrm{D}$

FIGURA 1. Frutos e sementes de Allophylus edulis (St.- Hil) Radlk.: A e D - fruto; B - semente; C - diferentes tamanhos do fruto e da semente.

comestível do fruto, com consistência pouca sucosa. Endocarpo ovóide, com ápice arredondado, base aguda e de coloração creme ao bege (Figura 1B). Endocarpo fino, quebradiço e não aderido ao tegumento da semente.

b) Morfologia da semente: (semente + endocarpo) retirando-se o endocarpo obtem-se a semente propriamente dita, recoberta por tegumento fino, papiráceo, de coloração laranja-escura. Semente ovóide, sem endosperma, estenospérmica e monocrômica. Hilo e micrópila visíveis e estão localizados na região basal. $\mathrm{O}$ embrião ocupa toda cavidade da semente, mais ou menos encurvado e levemente comprimido; cotilédones foliáceos de coloração amareloesverdeada; eixo-hipocótilo-radícula curto (Figuras 1B, 1C e 2C-J).

Nas Tabelas 1 e 2, encontram-se as dimensões do comprimento, largura e espessura do fruto e da semente, respectivamente.

c) Morfologia da germinação: Allophylus edulis apresenta geminação do tipo fanerocotiledonar e o início ocorre a partir de oito dias, após a semeadura. Com

TABELA 1. Dimensões do fruto de Allophylus edulis (St.- Hil) Radlk.

\begin{tabular}{lccccc}
\hline Dimensões $(\mathrm{mm})$ & Média & Máximo & Mínimo & Desvio Padrão & Coeficiente de variação \\
\hline Comprimento & 8,49 & 9,63 & 6,35 & 0,60 & 7,06 \\
Largura & 8,16 & 9,66 & 5,88 & 0,66 & 8,08 \\
Espessura & 7,54 & 9,36 & 5,49 & 0,62 & 8,22 \\
\hline
\end{tabular}

TABELA 2. Dimensões da semente de Allophylus edulis (St. - Hil) Radlk.

\begin{tabular}{lccccr}
\hline Dimensões $(\mathrm{mm})$ & Média & Máximo & Mínimo & Desvio Padrão & Coeficiente de variação \\
\hline Comprimento & 7,46 & 8,65 & 5,57 & 0,70 & 9,38 \\
Largura & 5,60 & 7,06 & 4,27 & 0,74 & 13,21 \\
Espessura & 4,98 & 7,74 & 3,09 & 0,67 & 13,45 \\
\hline
\end{tabular}




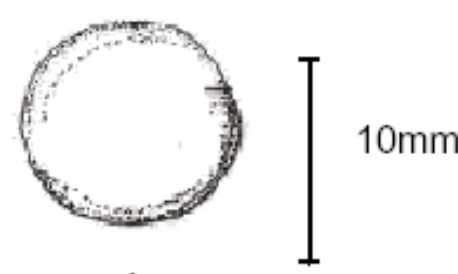

A

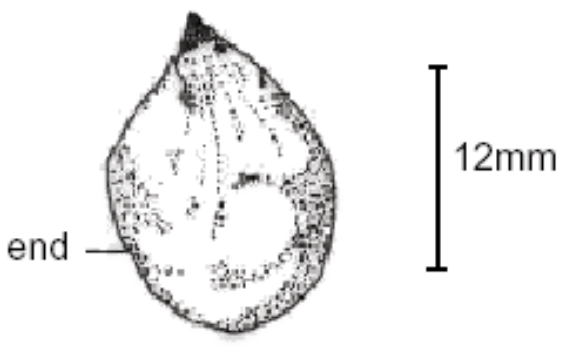

C

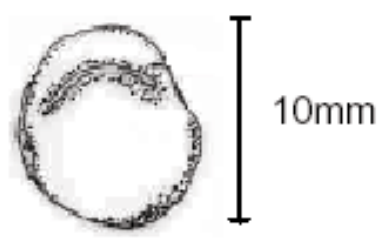

B

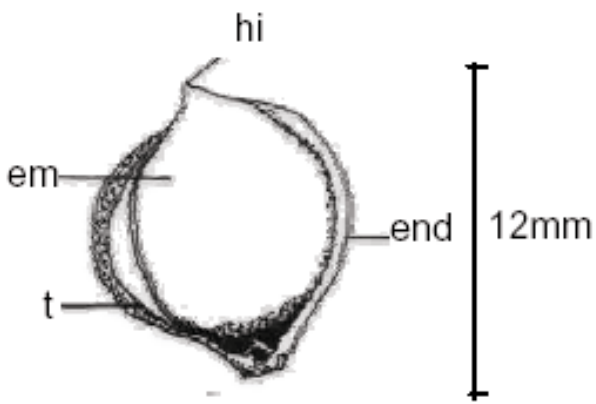

D

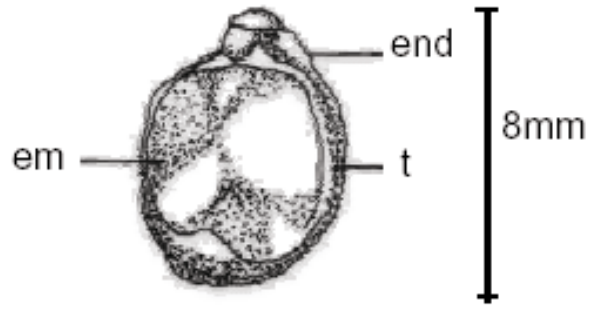

E

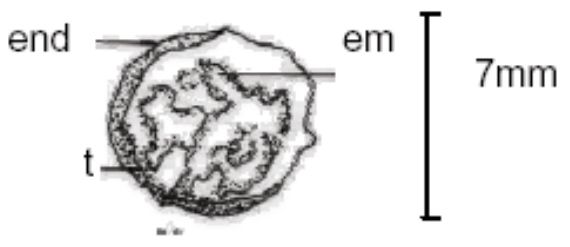

$\mathrm{H}$

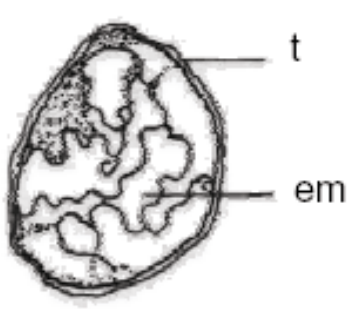

F
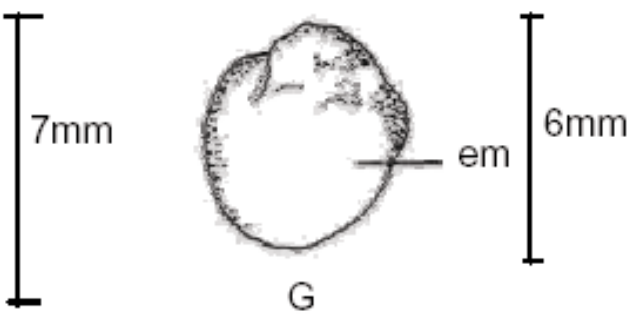

G

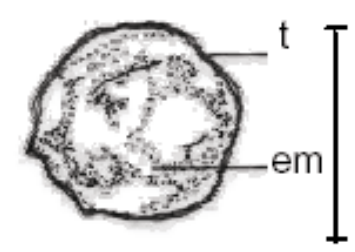

I

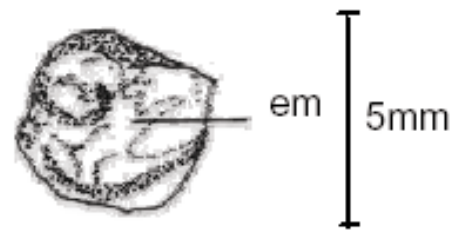

J

FIGURA 2. Morfologia do fruto e da semente de Allophylus edulis (St.-Hil.) Radlk.: A-B - fruto; C - semente;D-E-F-G - corte longitudinal da semente; H-I-J - corte transversal da semente. Legenda: c - cotilédone; em - embrião; end - endocarpo; hi - hilo; t tegumento 


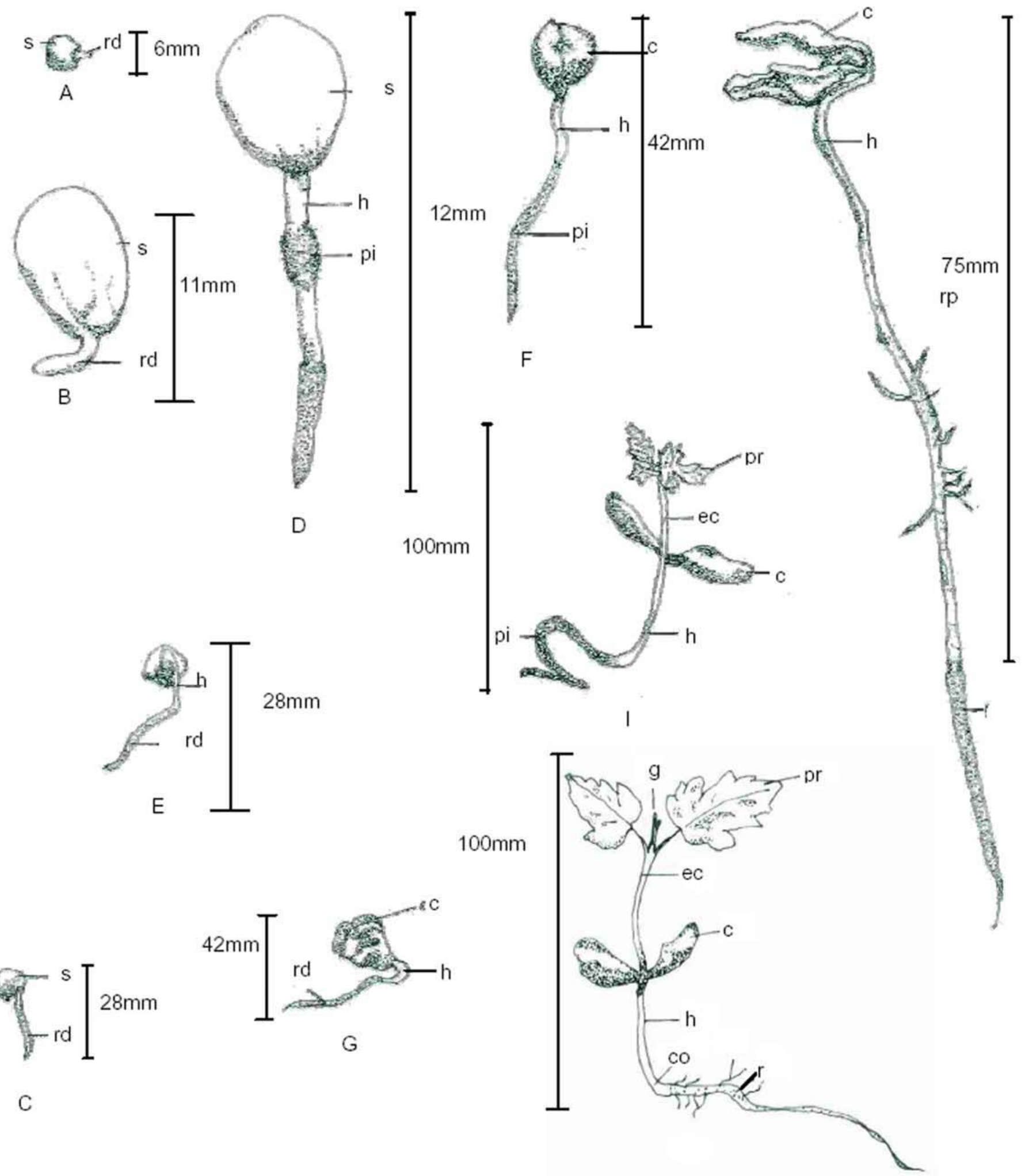

FIGURA 3. Morfologia da germinação de Allophylus edulis (St.-Hil.) Radlk.: A-B-C-D-E-F-Gestágios da germinação; H-I-J - plântula. Legenda: c - cotilédone; co - colo; ec epicótilo; g - gema apical; $\mathbf{h}$ - hipocótilo; pi - pêlos; pr - protófilo; r - raiz axial; rd radícula; rp - raiz primária; rs - raiz secundária; $s$ - semente 
a reidratação, o embrião retoma seu crescimento e a radícula rompe o tegumento. Radícula glabra, cilíndrica, vigorosa, de coloração esbranquiçada brilhante, que se alonga e forma uma curva para baixo, nessa fase tem $0,4 \mathrm{~cm}$ de comprimento (Figura 3A-B). Até os 14 dias de semeadura, o hipocótilo e a radícula estão mais alongados, medindo, aproximadamente, 2,8cm de comprimento (Figura $3 \mathrm{C}$-E). Hipocótilo cilíndrico, de coloração branca-esverdeada, que aos 16 dias de semeadura atinge 4,2cm de comprimento (Figura 3 F-G), eleva os cotilédones envolvidos pelo endocarpo, que se desprendem parcialmente. Aos 22 dias de semeadura, os cotilédones verdes, crassos e dobrados vão se expandindo até abrirem totalmente, surgindo entre eles a gema apical, pilosa e de coloração verde. Nesta fase, a plântula tem $7,5 \mathrm{~cm}$ de comprimento (Figura $3 \mathrm{H}$ ). Após esse período, a plântula já possui o epicótilo, hipocótilo, raiz e os protófilos, medindo $10 \mathrm{~cm}$ (Figura 3I-J). Sistema radicial pivotante, raiz axial longa, fina, sinuosa, esbranquiçada, caracterizada por um afinamento, com pêlos radiciais desenvolvidos. Raiz principal e raízes secundárias de coloração creme. Raiz secundária com pouca ramificação lateral, curtas e finas. Colo cilíndrico e sub-glabro, a delimitação entre o colo e o hipocótilo é nítida pela diferença na coloração. Hipocótilo longo, sub-herbáceo, cilíndrico, viridescente, levemente tortuoso próximo à inserção dos cotilédones. Cotilédones crassos, foliáceos, de coloração verde-escura. Epicótilo longo, fino, reto e liso, com a mesma coloração do hipocótilo e tornando-se ereto à medida que se erguem os protófilos. Os protófilos são desenvolvidos, verdeescuros, opostos, compostos, peciolados, lanceolados com bordas serreadas, ápice acuminado e base aguda (Figura 3IJ).

\section{CONCLUSÕES}

Os frutos de Allophylus edulis são do tipo coca globosa, indeiscente e monospérmica.

As sementes de $A$. edulis são ovóides, sem endosperma e o embrião ocupa toda a semente, mais ou menos encurvado e levemente comprimido.

A germinação das sementes de $A$. edulis é do tipo fanerocotiledonar, tem início ao oitavo dia e pode ser encerrada no décimo quinto dia, após a semeadura.

\section{AGRADECIMENTOS}

Os autores agradecem ao Centro Nacional de Pesquisas Florestais (CNPF) - Embrapa-Florestas por todo apoio e à concessão da infra-estrutura laboratorial na execução deste trabalho. À Universidade Federal do Paraná, pela realização do curso e à CAPES, pela concessão da bolsa de estudos.

\section{REFERÊNCIAS}

AMORIM, I.L.; Morfologia de frutos, sementes, germinação, plântulas e mudas de espécies florestais da região de Lavras MG. 1996. 127f. Dissertação (Mestrado em Engenharia Florestal) Departamento de Silvicultura, Universidade Federal de Lavras, Lavras, 1996.

AMORIM, I.L.; DAVIDE. A. C.; CHAVES, M. M. F. Morfologia do fruto e da semente, e germinação da semente de Trema micrantha (L.) Blum. Revista Cerne, Lavras, v.3, n.1, p.129-142, 1997.

ARAUJO, S.S. MATOS, V.P. Morfologia de sementes e de plântulas de Cassia fistula L. Revista Árvore, Viçosa, v.15, n.13, p.217-230, 1991.

BACKES, A.; NARDINO, M. Nomes populares e científicos de plantas do Rio Grande do Sul. São Leopoldo: UNISINOS, 1999. 202p.

BARROSO, G.M. Curso de identificação de sementes. Pelotas: UFPel, 1978a. 36p.

BARROSO, G.M.; MORIM, M.P.; PEIXOTO, A.L.; ICHASO, C.L.F. Frutos e sementes: morfologia aplicada à sistemática de dicotiledôneas. Viçosa: UFV, 1999. 443p.

BELTRATI, C.M. Morfologia das sementes e de sua germinação, em dezoito espécies de Eucalyptus. 1973. 236f. Dissertação (Mestrado em Ciências) - Faculdade de Filosofia e Letras de Rio Claro, Rio Claro, 1973.

BELTRATI, C.M.; Morfologia e anatomia de sementes. Rio Claro: UNESP, 1992. 108p. Apostila do Curso de Pós-graduação.

CHAVES, M.M.F. Descrição morfológica de sementes, de plântulas e de mudas de $\mathbf{1 0}$ espécies arbóreas pioneiras, na microrregião de Viçosa-MG. 1994. 108f. Dissertação (Mestrado em Ciências Florestais) - Departamento de Engenharia Florestal, Universidade Federal de Viçosa, Viçosa, 1994.

DONADIO, N.M.M.; DEMATTÊ, M.E.S.P. Morfologia de frutos, sementes, e plântulas de canafístula (Peltophorum dubium (Spreng.) Taub.) e jacarandá-da-Bahia (Dalbergia nigra (Vell.) Fr. All. ex Benth.) - Fabaceae. Revista Brasileira de Sementes, Brasília, v.22, n.1, p.64-73, 2000.

FELICIANO, A.L.P. Estudos da germinação de sementes e desenvolvimento da muda, acompanhamento de descrições morfológicas de 10 espécies arbóreas ocorrentes no semi-árido nordestino. 1989. 114f. Dissertação (Mestrado em Engenharia Florestal) Universidade Federal de Viçosa, Viçosa, 1989.

FERREIRA, R.A.; BOTELHO, S.A.; DAVIDE, A.C.; MALAVASI, M. de M. Caracterização morfológica de fruto, semente, plântula e muda de Dipteryx alata Vogel - baru (Leguminosae Papilionoideae). Revista Cerne, Lavras, v.14, n.1, p.7-87, 1998. 
FRANCO, I.J.; FONTANA, V.L. Ervas \& plantas: a medicina dos simples. 6.ed. Erexim: Edelbra, 2001.207p.

KÖRBES, V.C. Plantas medicinais. 48.ed. Francisco Beltrão: Associação de Estudo, Orientação e Assistência Social, 1995. $188 \mathrm{p}$.

KUNIYOSHI, Y.S. Morfologia da semente e da germinação de 25 espécies arbóreas de uma floresta de araucária. 1983. 233 f. Dissertação (Mestrado em Ciências Florestais) Departamento de Engenharia Florestal, Universidade Federal do Paraná, Curitiba, 1983.

LONGHI, R.A. Livro das árvores e arvoretas do sul. Porto Alegre: L \& PM, 1995. 176p.

LORENZI, H. Árvores brasileiras: manual de identificação e cultivo de plantas arbóreas nativas do Brasil. Nova Odessa: Plantarum, 1992.368p.

MORAES, P.L.R.; PAOLI, A.A.S. Morfologia de frutos e sementes de Cryptocaria moschata Nees \& Martius. Endlicheria paniculata (Sprengel) MacBride e Ocotea catharinensis Mez (LAURACEAE). Revista Brasileira de Sementes, Brasília, v.18, n.1,p.17-27, 1996.

OLIVEIRA, E. C. Morfologia de plântulas florestais. In: AGUIAR, I.B.; PIÑA-RODRIGUES, F.C.M. (Ed.) Sementes florestais tropicais. Brasília: ABRATES, 1993. p.75-214.

REITZ, P.; KLEIN, R.M.; REIS, A. Projeto Madeira do Rio Grande do Sul. [Porto Alegre]: SUDESUL; [Itajaí]: Herbário Barbosa Rodrigues, 1988. 423p.

REITZ, P. Sapindacea. Itajai: Herbário Barbosa Rodrigues, 1980. 156p. (Flora Ilustrada Catarinense).

SANCHOTENE, M.C.C. Frutíferas nativas úteis à fauna na arborização urbana. Porto Alegre: SAGRA, 1989. 163p.

SILVA, L.M. de M.; MATOS, V.P.; PEREIRA, D.D.; LIMA, A.A. Morfologia de frutos, sementes e plântulas de Luetzelburgia auriculata Duck. (pau-serrote) e Pterogyne nitens Tul. (madeira nova do brejo) Leguminosaceae. Revista Brasileira de Sementes, Brasília, v.17, n.2, p.154-159, 1995.

VIDAL, W.N.; VIDAL, M.R.R. Botânica: organografia. 4.ed. Viçosa: UFV, 2000. 114p. 